\title{
O significado do cuidado musical no contexto da extensão acadêmica de enfermagem - um relato de experiência
}

\section{The meaning of musical care in the context of academic nursing extension - an experience report}

\section{El significado de la atención musical en el contexto de la extensión académica de enfermería - un relato de experiencia}

\section{Gizélia da Gama Meira ${ }^{1 *}$, Chrisne Santana Biondo², Juliana Xavier Pinheiro da Cunha ${ }^{3}$, Emanuelle Caires Dias Araújo Nunes ${ }^{4}$}

Como citar esse artigo. Meira, G. G; Biondo, C. S; da Cunha, J. X. P; Nunes, C. D. A. N. O significado do cuidado musical no contexto da extensão acadêmica de enfermagem - um relato de experiência. Revista Pró-UniverSUS. 2021 Jul./Dez.; 12 (2): $21-26$.

\section{Resumo}

Objetivo: descrever a experiência vivida durante a realização das visitas musicais no projeto de extensão Agrupamento Multidisciplinar de Acolhimento (AMA). Materiais e Métodos: estudo descritivo, do tipo relato de experiência, realizado a partir da vivência do projeto de extensão AMA, que se deu no período de fevereiro de 2017 a março de 2018, envolvendo discentes dos cursos de Enfermagem e Psicologia da Universidade Federal da Bahia, no cenário de um hospital geral do sudoeste baiano. Resultados: evidenciou-se sensações de bem-estar, felicidade, animação, alegria e entusiasmo durante a aplicação da atividade, expressadas através de sorrisos, palavras de gratidão e choro de emoção pelos pacientes e familiares, enquanto a equipe, essa relatava a necessidade de frequência maior das atividades. Discussões: a importância e os benefícios promovidos pelo uso da música durante o internamento hospitalar, tanto para pacientes, familiares e equipe de saúde, além disso, a inserção da musicoterapia na formação acadêmica promove uma assistência integral, ressignificando as experiências acadêmicas no contexto hospitalar. Considerações finais: A realização das atividades demonstrou os aspectos positivos do cuidado musical, como a promoção de bem-estar físico, mental e espiritual no contexto terapêutico.

Palavras-chave: Assistência Integral à Saúde; Música; Empatia; Assistência Hospitalar.

\begin{abstract}
Objective: to describe the experience lived during the accomplishment of musical visits in the multidisciplinary reception grouping extension project (AMA). Materials and Methods: descriptive study, of the type of experience report, carried out from the experience of the AMA extension project, which took place from February 2017 to March 2018, involving students nursing and psychology courses at the Federal University of Bahia, in the scenario of a general hospital in southwestern Bahia. Results: feelings of well-being, happiness, animation, joy and enthusiasm were evidenced during the application of the activity, expressed through smiles, words of gratitude and crying of emotion by patients and family members, while the team, this reported the need for a higher frequency of activities. Discussions: the importance and benefits promoted by the use of music during hospitalization, both for patients, family members and health staff, in addition, the insertion of music therapy in academic training promotes comprehensive care, resignifying academic experiences in the hospital context. Final considerations: The performance of the activities demonstrated the positive aspects of musical care, such as the promotion of physical, mental and spiritual well-being in the therapeutic context.
\end{abstract}

Keywords: Comprehensive Health Care; Music; Empathy; Hospital Care.

${ }^{1}$ Enfermeira, residente no programa Uniprofissional de Enfermagem em Terapia Intensiva pela Secretária de Saúde da Bahia. Salvador, Bahia, Brasil. Email: giza_153@hotmail.com ORCID: https://orcid.org/0000-0003-4948-1426.

${ }^{2}$ Enfermeira, doutorando em ciências da saúde do Programa em Pós-Graduação em Enfermagem e Saúde da Universidade Estadual do Sudoeste da Bahia; Professora Assistente da Universidade Federal da Bahia. Vitória da Conquista, Bahia, Brasil. Email: tity_biondo_enf@hotmail.com ORCID: https://orcid.org/0000-0002-0583-5491.

${ }^{3}$ Enfermeira, doutoranda em epidemiologia pela Universidade Federal do Rio Grande do Sul, professora assistente da Universidade Federal da Bahia-UFBA. Vitória da Conquista, Bahia, Brasil. Email: julianaxcunha@gmail.com ORCID: https://orcid.org/0000-0002-3752-206X.

${ }^{4}$ Enfermeira, Doutoranda do Programa Interunidades da Escola de Enfermagem da Universidade de São Paulo, Bolsista CNPq. Professora Assistente da Universidade Federal da Bahia, Campus Anísio Teixeira. Vitória da Conquista, Bahia, Brasil. Email: emanuelecdanunes@gmail.com ORCID: 0000-0002-0226-3619.

* Email de correspondencia: giza_153@hotmail.com 


\section{Resumen}

Objetivo: describir la experiencia vivida durante la hazaña de visitas musicales en el proyecto de extensión de agrupación de recepción multidisciplinar (AMA). Materiales y métodos: estudio descriptivo, del tipo de informe de experiencia, realizado a partir de la experiencia del proyecto de extensión AMA, que tuvo lugar de febrero de 2017 a marzo de 2018, involucrando a estudiantes cursos de enfermería y psicología en la Universidad Federal de Bahía, en el escenario de un hospital general en el suroeste de Bahía. Resultados: sentimientos de bienestar, felicidad, animación, alegría y entusiasmo se evidenciaron durante la aplicación de la actividad, expresada a través de sonrisas, palabras de gratitud y llanto de emoción por parte de pacientes y familiares, mientras que el equipo, esto informó la necesidad de una mayor frecuencia de actividades. Debates: la importancia y beneficios promovidos por el uso de la música durante la hospitalización, tanto para pacientes, familiares y personal sanitario, además, la inserción de la musicoterapia en la formación académica promueve la atención integral, renunciando a las experiencias académicas en el contexto hospitalario. Consideraciones finales: La realización de las actividades demostró los aspectos positivos de la atención musical, como la promoción del bienestar físico, mental y espiritual en el contexto terapéutico.

Palabras clave: Atención Integral de Salud; Música; Empatía; Atención Hospitalaria.

\section{Introdução}

Desde o início das civilizações observa-se o uso da música em terapias da saúde, os primeiros relatos foram encontrados em papiros médicos egípcios, os povos primitivos acreditavam que a música tinha capacidade de livrar o doente da possessão de espíritos. Assim, evidencia-se que os elementos musicais como o ritmo, a harmonia e a melodia são capazes de levar a alterações fisiológicas, além de controlar a ansiedade e estresse, sendo um dos benefícios da música, assim, a sua utilização, como intervenção terapêutica, traz momentos de aconchego, relaxamento e tranquilidade, bem como a estimulação cognitiva por meio da memorização das letras musicais ${ }^{1}$.

A música atua sobre o manejo e controle da dor, apresenta diversos efeitos benéficos sobre a saúde do ser humano, além de contribuir para a melhora dos padrões respiratórios e no condicionamento físico, controlando ainda a ansiedade, tensão e estressse ${ }^{2}$. Seu uso no contexto terapêutico promove uma expressão de emoções, percepção da realidade e um equilíbrio interno $^{3}$. Outros autores complementam, afirmando que as visitas musicais, no âmbito hospitalar, foram se consolidando e se tornando cada vez mais frequentes, promovendo uma maior compreensão do indivíduo no contexto do sofrimento e enfrentamento hospitalar ${ }^{4}$.

Com essa nova estratégia de terapia, o cuidado humanizado no hospital tem-se concretizado cada vez mais, com isso, os pacientes e seus familiares têm uma melhora na qualidade de vida e em suas relações interpessoais, e o âmbito hospitalar se torna mais aconchegante e menos temível ${ }^{5}$. Portanto, com a humanização da assistência, se fazendo presente a partir do uso da música, o cliente é beneficiado na esfera biológica, psicológica e em seu contexto social, ou seja, em toda a sua integralidade ${ }^{6}$.

Nesse sentido, em 2017 é incluída, pela portaria $\mathrm{n}^{0} 849$, a musicoterapia à política nacional de práticas integrativa e complementar, contribuindo para incluir a música como recurso de cuidado junto a outras práticas, facilitando abordagens interdisciplinares, promovendo diálogo entre os indivíduos e profissionais?

No entanto, observa-se, que os estudos e pesquisas sobre musicoterapia estão aumentando gradativamente, contudo a prática do uso de músicas no âmbito hospitalar ainda não é tão comum. Com isso, espera-se que a partir da externalização desta experiência com a realização das visitas musicais, novos olhares e novos projetos surjam com esta temática, a fim de proporcionar bemestar físico, mental e espiritual para os pacientes, acompanhantes e profissionais. Espera-se também, que este trabalho seja capaz de fomentar maiores discussões sobre esta temática no âmbito acadêmico, para que os profissionais em saúde possam inserir as terapêuticas integrativas no cuidado integral em saúde na sua prática profissional.

Diante do exposto, o presente estudo objetivou descrever a experiência vivida durante a realização das visitas musicais no projeto de extensão Agrupamento Multidisciplinar de Acolhimento (AMA).

\section{Materiais}

O presente trabalho trata-se de estudo descritivo, do tipo relato de experiência, realizado a partir da vivência do projeto de extensão AMA, da Universidade Federal da Bahia - Instituto Multidisciplinar em Saúde, campus Anísio Teixeira (UFBA- IMS-CAT), instituto constituído somente por cursos da área de saúde, dos quais discentes e docentes apenas das áreas de Enfermagem e Psicologia compunham a equipe do projeto.

O AMA se apresenta como um projeto de extensão que tem como objetivo acolher as famílias com pessoas hospitalizadas em risco de morte a partir da práxis sistematizada do cuidado transpessoal-sistêmico. 
O cenário da experiência relatada compreende um hospital geral do sudoeste baiano, em que as atividades do projeto estavam direcionadas às famílias de pacientes graves ou terminais encontrados nos setores de internamento: clínica médica, cirúrgica e pediátrica; Unidades de Terapias Intensivas - UTIs (neonatal, pediátrica e adulto) e oncologia.

A unidade de internação escolhida para o relato de experiência foram as Clínicas médica, pediátrica, e UTIs adulto, por manter períodos mais longos de internação. Inúmeras atividades foram realizadas no projeto, tanto com os familiares que estavam acompanhando os pacientes e pacientes lúcidos, quanto com a própria equipe de profissionais dos setores. Dentre essas atividades, estavam as visitas musicais, que eram desenvolvidas uma vez por mês, em todos os setores do hospital, exceto emergência, por se tratar de um setor com alta rotatividade e ofertar atendimento aos pacientes, muitas vezes, em risco iminente de morte. Esse relato baseou-se nas experiências vivenciada no período de fevereiro de 2017 a março de 2018.

As visitas musicais eram planejadas e executadas pelo coordenador e colaboradores docentes e discentes do projeto. Era realizado, anteriormente, um levantamento das sugestões de músicas e estilos desejados pelos pacientes/familiares, e a partir dessa pesquisa informal, escolhiam aquelas canções que o grupo do projeto, por não ser profissional, conseguiam cantar e tocar. Assim, realizavam-se ensaios prévios e finalmente, desenvolviam-se a visita musical a beira leito, realizadas na modalidade voz (coral) e violão.

Os aspectos éticos foram respeitados na íntegra, de acordo com a resolução 466/2012 do Conselho Nacional de Saúde (CNS), e a presente pesquisa foi aprovada pelo Comitê de Ética e Pesquisa do Instituto Multidisciplinar em Saúde da Universidade Federal da Bahia (CEP-IMSUFBA), mediante parecer número 2.647.073 e CAAE 82481417.7.0000.5556, constituindo um subprojeto da pesquisa intitulada "Visita musical hospitalar como estratégia de cuidado transpessoal: significado para a formação e atuação em saúde".

\section{Resultados}

A sistematização das visitas musicais acontecia no turno vespertino, no horário das $14 \mathrm{~h}$ às $18 \mathrm{~h}$, em cada uma das enfermarias, de cada setor. Antes da entrada nas enfermarias, os pacientes e familiares eram informados sobre a atividade e se eles gostariam de participar deste momento, assim eram cantadas 02 músicas do repertório planejado.

O repertório era planejado, a partir de uma sondagempreviaaos pacientesquandoeramquestionados sobre seus interesses e relações com a música, e por qual estilo de música ou gênero teriam afinidade. A maioria dos pacientes lúcidos e dos acompanhantes relatava se interessar pelos gêneros gospel, sertanejo, forró e Música Popular Brasileira - MPB.

O desenvolvimento das visitas musicais com os pacientes e familiares durante o internamento hospitalar possui como pilar o cuidado integral abrangendo as dimensões biopsicossociais, seguindo a ótica da Teoria do Cuidado Transpessoal da enfermeira Dra. Jean Watson, sendo esta teoria referencial do projeto.

É importante salientar que um dos focos do projeto era o cuidado à família. Por isso, as visitas musicais aconteciam no horário em que o paciente estivesse em visita, para que o familiar também se sentisse cuidado. Durante as atividades percebia-se que a visita musical aproximava o familiar do seu ente querido, que estava internado, mobilizando ações de carinho que eram estimuladas durante a visita.

O primeiro espaço hospitalar onde foi realizada a atividade musical foi no isolamento da clínica médica, na área externa às enfermarias, no entanto, foi possível que os pacientes, seus acompanhantes e a equipe profissional pudessem acompanhar e ouvir as músicas.

Durante a atividade musical foi possível observar inúmeros sentimentos e reações apresentados pelos pacientes que se encontravam lúcidos e por seus acompanhantes. Reações como alegria, entusiasmo e animação eram observados através dos sorrisos que davam, e da forma como eles acompanhavam e cantavam junto as músicas. O choro e a emoção dos hospitalizados foram sentimentos que eles externalizaram durante a atividade, sentimentos que eram compartilhados pelas integrantes do projeto.

As visitas musicais se estendiam ainda pela pediatria e envolvia um repertório voltado para crianças, foi evidenciado sentimentos como diversão, bem-estar, felicidade, animação e entusiasmo, durante a aplicação da atividade.

As UTI's também foram o foco das atividades musicais desenvolvidas pelo projeto. Diferente dos outros setores, em determinados momentos, surgiram algumas situações que dificultaram e até impossibilitaram a realização das atividades musicais nesse local, que internam pacientes com instabilidade hemodinâmica que descompensavam e necessitavam de cuidados imediatos com mobilização da equipe. No entanto, sempre que possível e com permissão da equipe de profissionais as visitas musicais aconteciam.

Durante os momentos nas UTI's pôde-se perceber a reação dos pacientes que se encontravam lúcidos e responsivos, eles demonstraram expressões faciais que variavam desde alegria e felicidade à emoção e choro. Os visitantes que se encontravam à beira do leito ficavam visivelmente emocionados, alguns acompanhavam as músicas de mãos dadas com o familiar internado. Por falta de recursos humanos e materiais no projeto não foi possível avaliar os parâmetros vitais dos pacientes 
sedados durante as visitas musicais.

É válido salientar que os profissionais de saúde que ali se encontravam também acompanhavam a atividade, e externalizavam sentimentos de emoção e choro. Sendo considerado algo positivo, uma vez que os objetivo das visitas musicais é beneficiar positivamente não só os pacientes, mas todos que estão envolvidos no cuidado e na assistência

Assim, ao final das visitas nos setores envolvidos, observava-se que o público se mostrava agradecido e a equipe relatava que deveria aumentar a frequência dos encontros, devido os benefícios por eles produzidos. Além disso, foi observado o aumento da fé e esperança diante a hospitalização, evidenciando os benefícios do cuidado mente-corpo-espírito.

A realização das visitas musicais proporcionava aos integrantes do projeto inúmeros sentimentos positivos, sensação de bem-estar e emoção, semelhante aos vivenciados pelos pacientes, familiares e profissionais.

As músicas traziam paz, tranquilidade, fazendo uma conexão maior com a espiritualidade, que se faz de grande importância. Dessa forma, enfatiza-se a quão importante e benéfico foram as visitas, para o crescimento profissional e pessoal dos integrantes do projeto. Ao ouvir as músicas muitas lembranças da infância e que marcaram momentos da vida se faziam presentes naquele momento.

No ambiente hospitalar os profissionais se deparam com muitas situações que os abalam fisicamente e psicologicamente, a musicoterapia era uma fuga temporária desses momentos. Assim observase que as vivências na prática da musicoterapia foram significantes e transformadoras, sentimentos como empatia, humanização, esperança e fé, se intensificaram ainda mais com as visitas musicais, e ressignificaram a prática assistencial dos integrantes do projeto, tornando-a mais humana e menos tecnicista.

\section{Discussão}

A Teoria do Cuidado Transpessoal objetiva um cuidado integral, que ultrapasse a dimensão física, material, biológica do indivíduo, e busca alcançar um cuidado que valorize as necessidades subjetivas e espirituais ${ }^{8}$. Nesse sentido, observa-se a ideia de cuidado não apenas como ciência, mas como arte, uma relação que busca uma prática terapêutica eficaz em todas as dimensões do paciente, física, mental e espiritual ${ }^{9}$.

Desse modo, a atividade musical vai de encontro aos preceitos desta teoria, por estimular o bem-estar físico, psíquico e emocional dos participantes, tendo como facilidade o interesse de grande parte daqueles que se encontram no âmbito hospitalar. Assim, é indiscutível a importância da musicoterapia para a promoção de um outro tipo de cuidado, que vá além dos medicamentos ${ }^{10}$.

A relação com o bem-estar físico e mental e a qualidade de vida são aspectos definidos na dimensão da espiritualidade, quando são aplicadas atividades musicais observou-se a liberação de emoções e criação de insights sobre questões existenciais, indicando melhorias nos cuidados espirituais, na autoestima, empoderamento, conexão com algo maior, instilação de esperança, motivação, reflexões sobre cura, mente, corpo, alma, bem-estar espiritual e saúde integral. Quando analisados sob a ótica do paciente no contexto hospitalar, evidenciou-se associação ao otimismo em relação ao tratamento de doenças ${ }^{11}$.

Destarte, integrar a espiritualidade na experiência saúde-doença de um indivíduo pode ser uma ferramenta facilitadora para ele, apegando-se à fé ou a outro ponto de apoio, aumenta-se a sua capacidade de significar esse processo, assim, a música muitas vezes é relatada como opção utilizada nesse processo.

Embora as atividades tivessem o intuito de atender os indivíduos internados, foi possível notar o interesse dos profissionais. Como no isolamento, as visitas eram realizadas no corredor, a equipe de trabalhadores também participava e vivenciava esta experiência. Nesse contexto, a música contribui de forma que possa propiciar um cuidado humanizado por parte dos profissionais de saúde, além de proporcionar a eles redução dos níveis de estresse ocasionados pelo ambiente de trabalho ${ }^{12}$

A escolha musical de um indivíduo é uma forma de demonstrar algo que traz sentido para sua vida, e que reflete sua singularidade, identidade, e permitindolhe criar memórias de sentimentos ligados aos eventos importantes vividos ${ }^{13}$. A partir disso, ao serem realizadas as visitas nas demais enfermarias das clínicas médica e cirúrgica, procurou-se atender, sempre que possível, os interesses dos que ali se encontravam.

A música é considerada uma forma de arte, que proporciona ao indivíduo bem-estar e alegria, sendo considerada um instrumento com inúmeros benefícios para os que se encontram em internamento hospitalar ${ }^{5}$.

As reações de alegria, entusiasmo e animação demonstrado pelos familiares, sorrindo e cantando junto com o coral, externalizavam os benefícios da atividade para eles. Os aspectos benéficos proporcionados pela música são observados desde a externalização de sentimentos como o choro, tristeza, alegria, raiva; ao bem-estar físico e psicológico, como relaxamento, diminuição da agitação e do cansaço ${ }^{4}$. Outrossim, a música não é só tida como um passatempo usada para distração e diversão, ela é considerada uma alternativa para promover boas sensações ${ }^{14}$.

Outro setor beneficiado com as visitas musicais, foi a pediatria, a internação hospitalar para uma criança e sua família provoca um impacto negativo, uma vez 
que o hospital é um ambiente desconhecido, com regras, espaços e pessoas diferentes ${ }^{15}$, diante desse cenário, nas visitas musicais, evidenciou-se a participação das crianças e seus cuidadores cantando as músicas, algumas crianças participavam dançando ou eram embaladas pelos cuidadores durante a atividade.

Gestos como pular, dançar, cantar, bater palmas, foram realizados por elas, inferindo os benefícios promovidos pela música. Portanto, além dos impactos positivos às crianças, o canto musical também promove benefícios aos seus familiares ${ }^{16}$.

A musicoterapia é uma tática de cuidado não farmacológico que vem sendo utilizada e implementada a cada dia, buscando alcançar resultados positivos na recuperação e desenvolvimento da criança. Sendo constatado os efeitos benéficos na estabilização dos sinais vitais, interesse com o meio e na redução do estresse, além do bem-estar ${ }^{15}$.

O ambiente da UTI, local onde eram realizados também as visitas musicais, pode levar os pacientes, que se encontram internados, à apresentarem sentimentos desagradáveis, devido aos inúmeros fatores contribuintes como, a gravidade do quadro clínico, o cuidado prestado por pessoas desconhecidas e pouco contato com os familiares, uma vez que eles só podem permanecer na UTI durante o horário de visitas ${ }^{17}$.

Na maioria das vezes, durantes as visitas musicais, os pacientes encontravam-se sob ventilação mecânica e sedados, o que não descarta os efeitos da música neles, e houve momentos em que alguns se encontravam lúcidos e conscientes.

Diante desse cenário, revisão de literatura realizada trouxe evidências que a musicoterapia é uma intervenção não farmacológica ideal para melhorar a tolerância dos pacientes à ventilação mecânica em quantidades reduzidas de sedação, além de ajudar na redução da hipertensão arterial, condição sistêmica comum em pacientes críticos, e influenciar na diminuição da pontuação da dor nesses pacientes, reduzindo o número de intervenções sedativas principalmente durante a aspiração endotraqueal ${ }^{18}$. Com isso, é possível inferir benefícios nesses pacientes durante as visitas musicais.

Ao levar a música para o ambiente hospitalar objetiva-se favorecer a recuperação do paciente, e acalmar os familiares que os visitam ${ }^{4}$. O recurso musical é considerado uma ferramenta de suma importância nos tratamentos de saúde que visam o cuidado holístico e humanizado, além de estar se tornando cada vez mais um instrumento utilizado no âmbito hospitalar, outros autores complementam afirmando ser de extrema relevância a colaboração e motivação de todos os profissionais de saúde nas terapias musicais, de modo que eles interajam e contribuam na humanização e integralidade da assistência ${ }^{5,15}$.

Diante da experiência vivenciada, observa-se ainda que, os estudantes, que tiveram a oportunidade de participar desse projeto de extensão, estarão mais aptos a lidarem com a realidade que encontrarão quando tornar-se um profissional. $\mathrm{O}$ que possibilita ao acadêmico a experiência do contato entre o aprendizado na Universidade e a aplicabilidade na sociedade, contribuindo para sua compreensão como ser socialmente responsável, tendo seu aprendizado para a formação do cuidado integral em saúde ${ }^{19}$.

\section{Considerações Finais}

Com esse relato foi possível descrever e analisar os benefícios das visitas musicais aos pacientes, acompanhantes e profissionais sendo alcançado através da rica experiencia vivenciada durante a participação das atividades musicais. Dessa forma, o trabalho permitiu conhecer os sentimentos e emoções externalizados pelos pacientes, além ressaltar a relevância e eficácia do uso de novos instrumentos de cuidado para promoção de uma assistência integral e humanizada, proporcionando ganhos acadêmicos para inserir práticas integrativas na atuação profissional em saúde.

A realização das atividades demonstrou os aspectos positivos do cuidado musical, como a promoção de bem-estar físico e mental, fé e esperança diante a hospitalização, evidenciando os benefícios da musicoterapia no trinômio mente-corpo-alma.

Com isso, espera-se que a dinâmica musical se mostre ser uma estratégia efetiva de sensibilização dos profissionais, a fim de que promovam um cuidado que valorize todas as dimensões do paciente e de sua família, que vá além do tratamento medicamentoso e mecanicista. Em suma, é válido salientar a importância de implementar a música como uma forma de terapia alternativa, no âmbito hospitalar, uma vez que seus benefícios atingem tanto o paciente quanto a própria equipe de saúde.

\section{Referências}

1. de Jesus VV, da Silva Rodrigues A, Alencar RFC, Loureiro MAB, dos Santos Costa AV, da Costa Carvalho KA, Arouche WP. Impacto da musicoterapia em uma unidade de terapia intensiva em São Luís MA: relato de experiência. Brazilian Journal of Development. 2021; 7(2), 1690016907.

2. Teixeira MMR, Paula JMD, Vidal LM, Porto JAS, Júnior B,Vidal CEL. Efeitos Da Música No Pós-Operatório De Pacientes Hospitalizados. Rev Med Minas Gerais, 2018; 28(8): 1929.

3. Batista NS, Ribeiro MC. O uso da música como recurso terapêutico em saúde mental. Rev Ter Ocup Univ São Paulo. 2016 set.-dez.;27(3):33641.

4. Câmara YMR, Campos MRM, Câmara YR. Musicoterapia como recurso terapêutico para a saúde mental. Cadernos Brasileiros de Saúde Mental/Brazilian Journal of Mental Health, 2013; 5(12): 94-117.

5. Nascimento CAA, Crepalde NJBF. A Música Como Recurso nos Processos de Humanização Hospitalar. Revista Formação Docente. Belo 
Horizonte. Jan-Jun 2015; 7(1):24-35.

6. Cardoso AVM, Souza AAM, Silva PLN, Carvalho HLA, Alves ED, Filho WA. Cuidando com Arte: a promoção da saúde por meio da música. Revista da Universidade Vale do Rio Verde, Três Corações. 2016; 14(1): 714-735.

7. Brasil. Ministério da Saúde. Portaria $n^{\circ} 849$, de 27 de março de 2017. Inclui a Arteterapia, Ayurveda, Biodança, Dança Circular, Meditação, Musicoterapia, Naturopatia, Osteopatia, Quiropraxia, Reflexoterapia, Reiki, Shantala, Terapia Comunitária Integrativa e Yoga à Política Nacional de Práticas Integrativas e Complementares.

8. Watson J. Nursing: the philosophy and science of caring / Jean Watson. - Rev, ed. Published by the University Press of Colorado; 2008.

9. Favero L, Meier MJ, Lacerda MR, Mazza VA, Kalinowski LC. Aplicação da Teoria do Cuidado Transpessoal de Jean Watson: uma década de produção brasileira. Acta Paul. Enferm. 2009 fev/mar; 22(2): 213-8.

10. Pinto COM, Gazaneo L, Lamas M. Musicoterapia na humanização - Uma proposta de trabalho em hospital oncológico. ANPPOM - Décimo Quinto Congresso/2005.

11. Pismel MCG, Röpke J, Tomaselli TJ, Neves L, Pasqual FS, Vagetti GC. Musicoterapia e espiritualidade: uma revisão integrativa. Brazilian Journal of Music Therapy. 2018.; 25, 08-29.

12. Silva KG, Taets GGC, Bergold LB. A utilização da música em uma unidade pediátrica: contribuindo para a humanização hospitalar. Rev enferm UERJ, Rio de Janeiro, 2017; 25:e26265.

13. Bergold LB, Chagas M, Alvim NAT, Backes DS. A utilização da música na humanização do ambiente Hospitalar: interfaces da musicoterapia e enfermagem. Revista Brasileira de Musicoterapia. 2016; 9(9).

14. Rodrigues B, Isaac R. A influência da música nos métodos de cura da atualidade. Integratio. 2016; 2(2); 61-64.

15. Rodrigues DIS, Fófano GA, Barreiros LL, Couto CSF, Vieira CF, de Oliveira MAAC. A utilização da musicoterapia na assistência ao prematuro internado em unidade de terapia intensiva neonatal: uma revisão bibliográfica. Revista Científica UNIFAGOC-Saúde, 2018;3(1), 67-73.

16. Finger D, Souza JB, Berlezi GD, Zanettini A. Música, saúde, enfermagem: percepção familiar sobre o canto coral no desenvolvimento infantil. Rev enferm UFPE on line., Recife, ago., 2017.; 11(Supl. 8):3251-7.

17. Valença CN, Azevêdo LMN de, Oliveira AG de, Medeiros SSA de, Malveira FAS, Germano RM. Music therapy in nursing care in intensive care. R. pesq. cuid. fundam. online. 2013; 5(5), 61-68.

18. Mueller BR, Gaedke MÂ. Efeitos terapêuticos da musicoterapia em pacientes sob ventilação mecânica em unidade de terapia intensiva: uma revisão sistemática. Revista Ciência e Conhecimento. 2018; 12 (1), 77-89.

19. Canon CAS, Pelegrinelli G. Extensão universitária: o impacto de um projeto de extensão na formação profissional dos discentes na educação superior. Revista UFG. 2019; 19:1-15. 